\title{
'Floating' left atrial appendage in an infant with chylopericardium
}

\author{
I B Vijayalakshmi, Navin Agrawal, Kavya Mallikarjun, Cholenahally N Manjunath
}

Department of Cardiology, Sri Jayadeva Institute of Cardiovascular Sciences and Research, Bangalore, Karnataka, India

\section{Correspondence to} Dr Navin Agrawal, drnavinagrawal@gmail.com

\section{DESCRIPTION}

We present an interesting image of a 'floating left atrial (LA) appendage' in a 5-month-old female infant with pericardial tamponade. Clinical features of respiratory distress, lethargy and difficulty in suckling were present and the jugular venous pressure (JVP) was raised, although the wave forms were not easily assessable due to the child being in respiratory distress and uncooperative.

The echocardiographic evaluation revealed the signs of tamponade along with another interesting finding that the left atrial appendage (LAA) was elongated and membrane like and was freely moving and ballooning with atrial contraction in the pericardial fluid around it as though 'floating'. Cath tracings were not performed as the first priority was an emergency lifesaving pericardiocentesis. There was another abnormal bulge posterolaterally.
The other cardiac chambers were normal and there was no obvious echocardiographic evidence of any pressure overload of LA in the form of LA dilation (figures 1 and 2; see videos 1-4).

Pericardiocentesis revealed the presence of chylous fluid. (figure 3). CT confirmed the finding and revealed no mediastinal or cardiac mass and no obvious thoracic duct anomaly (figure 4).

The child was planned for conservative management followed by thoracic duct ligation if required in view of the high surgical risk in exploratory thoracotomy in absence of a definite diagnosis and a definitive understanding of the pathophysiology.

On follow-up at 1 month the appendicular abnormality had recovered completely and the fluid had decreased.

This is an unusual interesting image of membranous LAA in an infant with large chylous PE.

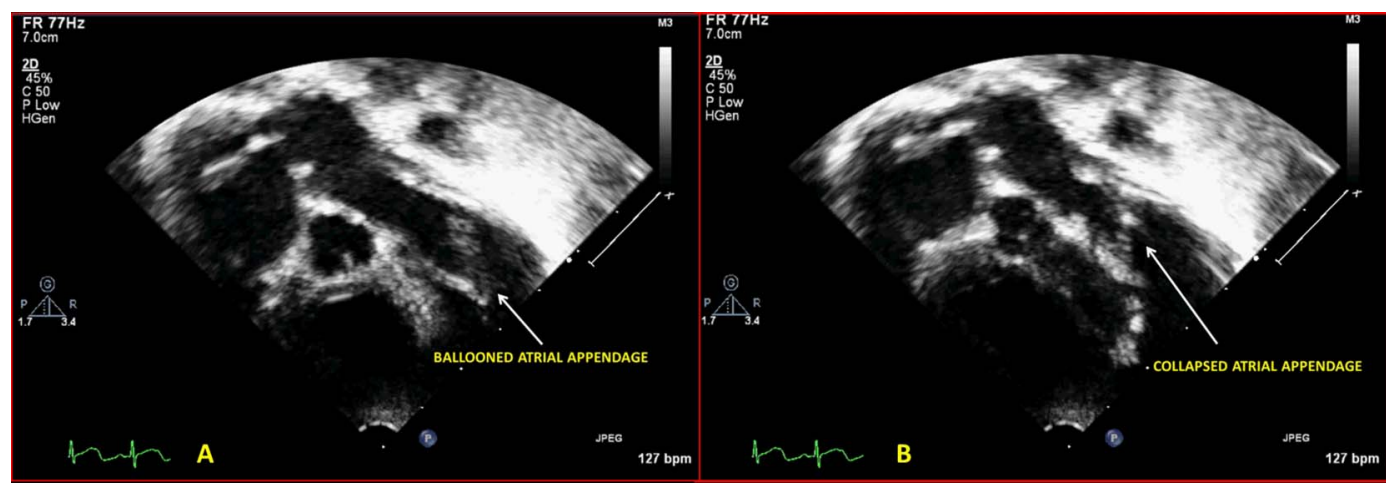

Figure 1 Comparative echocardiographic image in inverted apical four-chamber view showing the left atrial appendage in an expanded (A) and collapsed state (B).

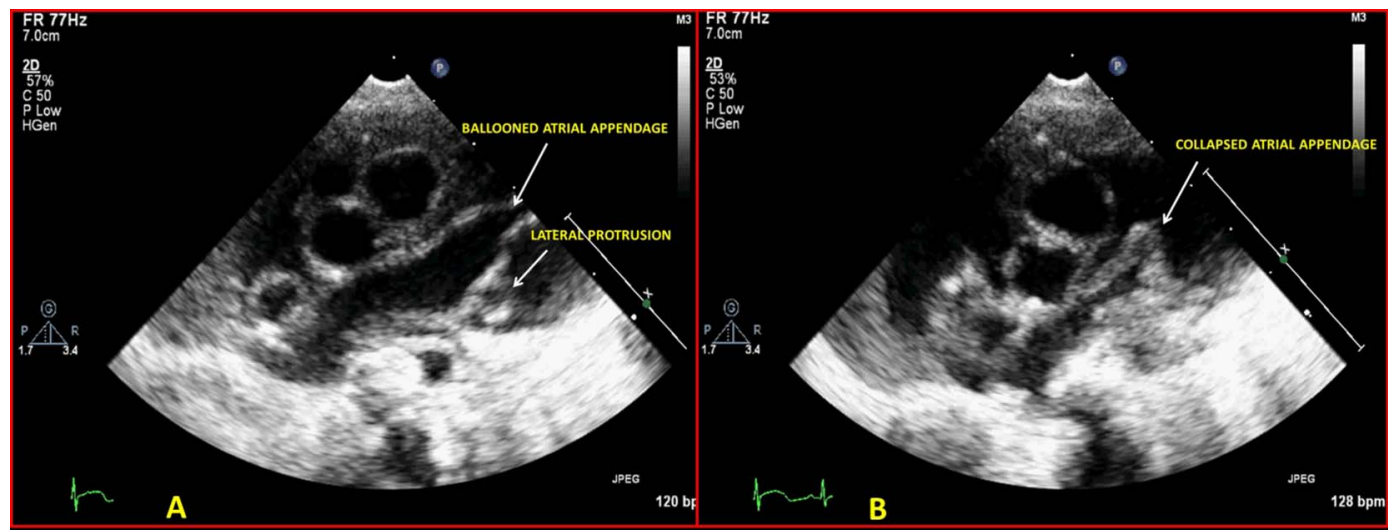

To cite: Vijayalakshmi IB, Agrawal N, Mallikarjun K, et al. BMJ Case Rep Published online: [please include Day Month Year] doi:10.1136/bcr-2013200275
Figure 2 Comparative echocardiographic image in modified parasternal short axis view showing the left atrial appendage in an expanded (A) and collapsed state (B). Arrow points to the abnormal bulge present laterally in the appendage. 


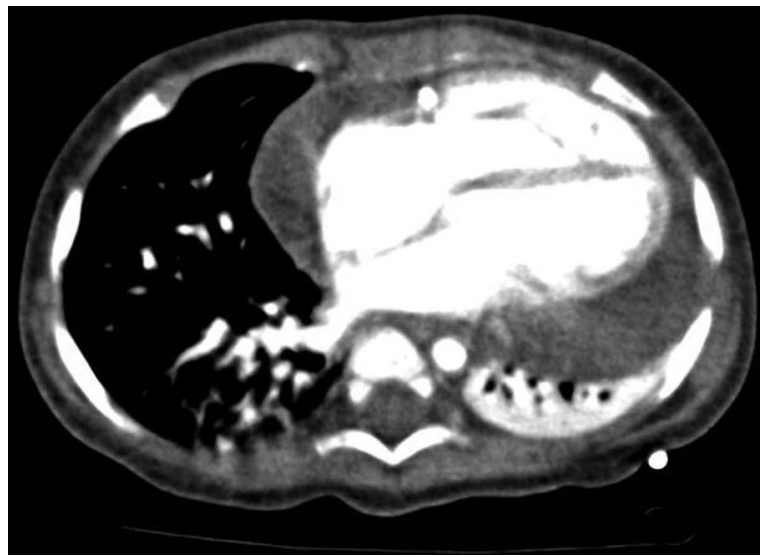

Figure 3 CT image of the mediastinum showing large pericardial effusion with no obvious coexistent abnormality.

Inversion ${ }^{1}$ and aneurysm of LAA containing clot have been previously reported but to the best of our knowledge 'floating' and ballooning of the LAA in the presence of chylopericardium have never been reported. Abnormality of LAA as seen in this infant caused diagnostic dilemma for its cause and despite extensive literature review, a plausible explanation for this entity could not be obtained.

This entity is interesting as it is a transient aberration of the morphology of the LA appendage which has not been described previously and pathophysiological assessment may lead to a better understanding of the interaction of the pericardial fluid with the left-sided cardiac structures different from those on the right side.

Pericardial tamponade is characterised by ECG manifestation of low-voltage complexes and electrical alternans and X-ray demonstrates 'Flask' like appearance of the heart with oligemic lung fields.

Echocardiographically it presents with diastolic collapse of the right atrium (sensitive sign) and the right ventricle (specific sign) and distended and non-collapsing vena cavae.

Prominent $\mathrm{X}$ descent and absent $\mathrm{Y}$ descent and absent Kussmaul's sign are important diagnostic feature of cardiac tamponade in JVP. These findings can be confirmed on cath and the absence of square root sign is also an important feature seen in patients with cardiac tamponade which helps to differentiate tamponade from patients with restrictive cardiomyopathy and constrictive pericarditis.

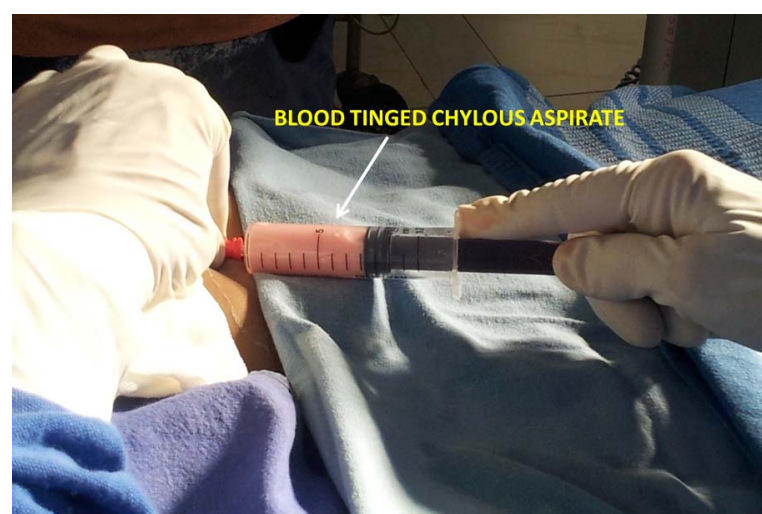

Figure 4 Chylous fluid collected during pericardiocentesis in the infant at the time of presentation.

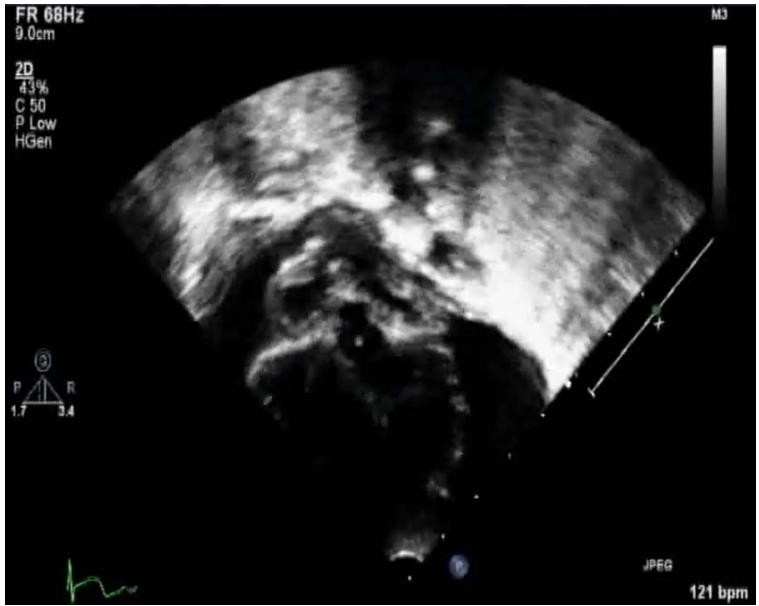

Video 1 Apical four chamber view is showing the LA appendage ballooning out with every atria contraction and apparently floating in the pericardial fluid.

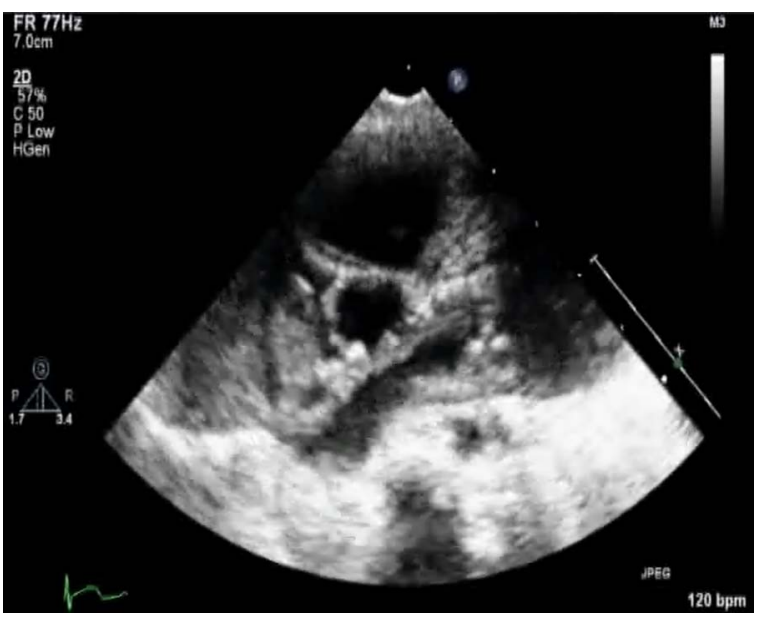

Video 2 Modified parasternal short axis view showing the LA appendage ballooning out with every atria contraction with an abnormal LA appendage bulge laterally present.

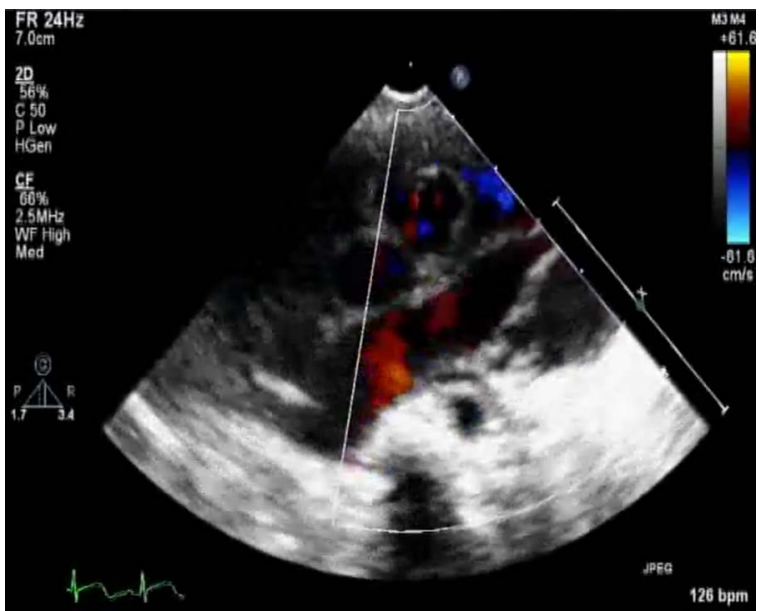

Video 3 Modified parasternal short axis view with colour Doppler flow demonstrated across the blood flow across the LA appendage. 


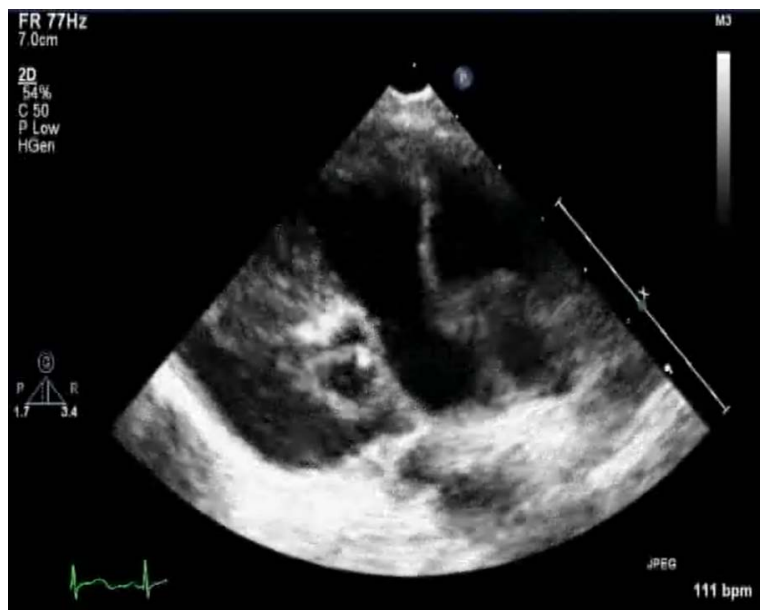

Contributors All the authors have contributed in the drafting of the manuscript and in patient care.

Competing interests None.

Patient consent Obtained.

Provenance and peer review Not commissioned; externally peer reviewed.

\section{REFERENCES}

1 Gecmen C, Candan 0, Guler A, et al. Unusual left atrial mass: inverted left atrial appendage caused by massive pericardial effusion. Echocardiography 2011;28: E134-6.

2 Reddy PS, Curtiss El, O'Toole JD, et al. Cardiac tamponade: hemodynamic observations in man. Circulation 1978;58:265-72.

3 Meltser H, Kalaria VG. Cardiac tamponade. Catheter Cardiovasc Interv 2005;64:245-55

Video 4 Modified parasternal long axis view showing the ballooning of the LA appendage on the lower surface.

There is equalisation of diastolic pressures in all chambers. The flow in vena cavae also becomes monophasic and is confined to ventricular systole, corresponding to the $\mathrm{X}$ descent. $^{2}{ }^{3}$ Other haemodynamic changes that have been described in pericardial tamponade are out of phase right ventricular and left ventricular peak systolic pressures, peak aortic pressure varying more than 10-12 $\mathrm{mm} \mathrm{Hg}$ and decreased cardiac output.

\section{Learning points}

- Massive pericardial effusion can cause morphological alterations in the left atrial (LA) appendage but the pathophysiology of such change needs to be assessed.

- Floating LA appendage as a morphological aberration needs further evaluation to assess for the interaction of the pericardial fluid with the left atrium and the left atrial appendage.

- CT and MRI may or may not be helpful in assessment of aetiopathogenesis although associated anomalies like the presence of a pericardial or mediastinal mass or other aberrations in the thoracic duct may be ruled out.

- Lymphangioscintigraphy is the modality of choice for assessment of idiopathic chylopericardium to assess for the thoracic duct anomalies although difficult to perform.

Copyright 2013 BMJ Publishing Group. All rights reserved. For permission to reuse any of this content visit http://group.bmj.com/group/rights-licensing/permissions.

BMJ Case Report Fellows may re-use this article for personal use and teaching without any further permission.

Become a Fellow of BMJ Case Reports today and you can:

- Submit as many cases as you like

- Enjoy fast sympathetic peer review and rapid publication of accepted articles

- Access all the published articles

- Re-use any of the published material for personal use and teaching without further permission

For information on Institutional Fellowships contact consortiasales@bmjgroup.com

Visit casereports.bmj.com for more articles like this and to become a Fellow 